\title{
Anne Conchon, La corvée des grands chemins au XVIII siècle. Économie d'une institution
}

Rennes, Presses de l'université de Rennes, 2016

\section{Michèle Virol}

\section{(2) OpenEdition}

12 Journals

Édition électronique

URL : http://journals.openedition.org/artefact/4278

DOI : 10.4000/artefact.4278

ISSN : 2606-9245

Éditeur :

Association Artefact. Techniques histoire et sciences humaines, Presses universitaires du Midi

Édition imprimée

Date de publication : 15 octobre 2019

Pagination : 224-227

ISBN : 978-2-8107-0650-1

ISSN : 2273-0753

Référence électronique

Michèle Virol, «Anne Conchon, La corvée des grands chemins au xvıle siècle. Économie d'une institution », Artefact [En ligne], 10 | 2019, mis en ligne le 06 août 2020, consulté le 01 décembre 2020. URL : http:// journals.openedition.org/artefact/4278; DOI : https://doi.org/10.4000/artefact.4278

Ce document a été généré automatiquement le 1 décembre 2020.

\section{cc) (1) $९$}

Artefact, Techniques, histoire et sciences humaines est mise à disposition selon les termes de la Licence Creative Commons Attribution - Pas d'Utilisation Commerciale - Pas de Modification 4.0 International. 


\title{
Anne Conchon, La corvée des grands chemins au XVIII siècle. Économie d'une institution
}

Rennes, Presses de l'université de Rennes, 2016

\author{
Michèle Virol
}

\section{RÉFÉRENCE}

Anne Conchon, La corvée des grands chemins au XVIII siècle. Économie d'une institution, Rennes, Presses de l'université de Rennes, 2016, 352 p.

1 Cet ouvrage tend à faire le point sur une institution instaurée en France au XVIII ${ }^{\mathrm{e}}$ siècle, la corvée royale, afin de réaliser le vaste projet de construction des routes du royaume. Après un premier chapitre qui étudie la création de la corvée royale, le second analyse le fonctionnement de cette réquisition. Cette prestation en travail exigée de tous les riverains des tracés des grands chemins dans les pays d'élections se met en place à la suite des décisions politiques et des règlements administratifs qui normalisent les prescriptions et les pratiques de travail dans les années 1720-1737. Elle devient le mode privilégié de construction et d'entretien des routes, plusieurs pays d'États l'adoptant, à l'exemple de la Bourgogne et de la Bretagne. Elle repose sur la réquisition de la maind'œuvre agricole inactive (hors semailles et moissons) pendant deux périodes de l'année (automne et printemps), ce qui ne devait causer aucun préjudice économique.

2 L'ouvrage montre clairement comment l'institutionnalisation de cette pratique accompagne le développement du département des Ponts et Chaussées qui est rattaché au Contrôle général en 1736. Dans un rayon de quelques lieues de part et d'autre de la route, les habitants des communautés riveraines doivent travailler gratuitement un certain nombre de jours par an à proportion de leur situation fiscale (taille) à la construction et à l'entretien des routes empierrées, les routes pavées et les ouvrages d'art étant financés par la monarchie. Ce modèle de réquisition de travail est largement 
emprunté aux réquisitions militaires. Les ingénieurs doivent mesurer la quantité de travail nécessaire en fonction du tracé, lui-même souvent proportionné à la maind'œuvre disponible. Ils sont formés à l'évaluation précise de chacune des tâches et ils évaluent les forces à réquisitionner en hommes et en bêtes. Les cartes de Cassini puis l'Atlas de Trudaine servent à délimiter les paroisses concernées par la corvée royale. De quatre lieues de part et d'autre de la route, la distance a été ramenée à deux lieues ou deux lieues et demie $(8-10 \mathrm{~km})$ pour la corvée à bras afin que les personnes réquisitionnées puissent rentrer dormir chez elles alors que pour la corvée de harnais (attelage pour transporter les matériaux) elle est fonction de la distance de la carrière à l'atelier. Le périmètre de réquisition est plus difficile à définir dans les zones peu densément peuplées et il peut être contesté par la population. L'administration locale de la corvée est confiée à des syndics parfois encore appelés voyers nommés par les "généraux de paroisse " qui ont compétence pour toutes les affaires communautaires. Les syndics sont responsables de la fiabilité des informations transmises (personnes, bêtes de bât et attelages).

3 Les ingénieurs doivent ensuite répartir le travail : affecter la population sur la route, répartir les ateliers et la tâche à imposer à telle ou telle communauté. Anne Conchon a étudié les nombreux plans de répartition de la main-d'œuvre complétés par les états de répartition ou de distribution conservés dans les archives départementales. Les outils administratifs créés pour cette corvée royale sont relativement normalisés pour exposer les informations collectées : distance entre la communauté et l'atelier, nombre de travailleurs, quantité de voitures, durée de la tâche.

4 Le regard de l'historienne se porte ensuite sur le travail des corvéables: l'aptitude physique exigée exclut en principe les enfants jusqu'à 16 ans, les plus de 60 ans, les malades et les infirmes, les femmes sauf les veuves et les célibataires, mais les exceptions sont nombreuses. La surveillance est dévolue aux conducteurs et aux piqueurs recrutés pour ces chantiers. Pénibilité, sanctions sont inventoriées, avant d'envisager les dysfonctionnements puis les premières expériences de rachat de la corvée.

5 Plus de la moitié du livre, du chapitre IV au chapitre vIII, est consacrée à la transformation progressive de la corvée royale, en rachat ou en imposition après des expériences diverses et de nombreux débats menés notamment par les physiocrates qui dénoncent la réquisition en travail comme contraire à la liberté. La France connaît des années difficiles après la guerre de Sept ans. La réforme de la taille, sur laquelle est adossée la corvée, est entreprise à partir de 1776, parallèlement au rachat de la corvée expérimenté dans les généralités de Caen et de Limoges, le montant de ce rachat étant calculé selon la richesse des corvéables (donc un impôt de quotité et non plus de répartition). Les travaux routiers vont être, dans ce cas, programmés en fonction de la contribution espérée des paroisses et non des besoins routiers.

6 Avant de consacrer un chapitre aux débats sur la corvée, cet ouvrage traite des documents comptables générés pour la gestion de la corvée, précieux pour les historiens : liste de défaillants, liste des paroisses concernées, travail accompli, coûts engendrés (fourniture et entretien des outils, salaires des personnels: piqueurs et conducteurs, indemnisation des accidents de travail), ce qui permettait à l'administration royale de connaître les dépenses supportées par la monarchie mais aussi d'organiser la programmation des travaux d'une année sur l'autre. Ces documents, au fil des années, sont de plus en plus structurés et révèlent 
progressivement une pensée qui intègre la hiérarchisation des voies mais aussi leur mise en relation jusqu'au réseau. Anne Conchon insiste sur l'efficacité de la corvée royale pour réaliser les routes, ainsi, en 1774, 6000 lieues $(23388 \mathrm{~km})$ de routes ont été construites (681 lieues de routes pavées et 5300 de routes empierrées). Contrairement à ce qu'ont écrit ses détracteurs, la corvée royale a été utile pour la construction des routes du royaume.

7 À partir du xvIII siècle, une cinquantaine de textes français ont été publiés sur la corvée royale, les débats occultant le travail réellement accompli et les détails de son fonctionnement, que cet ouvrage permet, à l'opposé, de connaître. Menée par les physiocrates au nom de l'équité, une critique vise à discréditer la corvée royale jugée préjudiciable à l'économie. Elle propose soit le rachat de la corvée sur le modèle de la généralité de Caen, soit sa fiscalisation à la charge des seuls propriétaires.

Il s'agit après la suppression de la corvée de travail par le contrôleur général des finances Turgot en 1776, de trouver les entrepreneurs qui, après adjudication vont faire réaliser les grands travaux routiers par une main-d'œuvre salariée. Puis, en 1786, la solution de l'impôt est adoptée pour supprimer l'inégalité de la seule prise en charge par les communautés riveraines de la route et faire participer les villes à la dépense.

9 Le recours à l'entreprise et au salariat va-t-il être plus efficace pour réaliser l'entretien des routes et leur construction? Les Physiocrates l'affirmaient, les ingénieurs des Ponts et Chaussées en doutaient. Anne Conchon tente de déduire des archives dont elle dispose une réponse, p. 303 «Il semble donc avéré que l'adjudication permit de réduire le coût du financement routier. Rien ne préjuge en revanche d'une plus grande productivité du travail et d'une meilleure qualité des ouvrages, que promettaient les tenants de la commutation (de la corvée en impôt)».

La Révolution interrompt cette réforme très récente, rendant difficile son évaluation. Les hommes qui travaillent sont les mêmes: corvéables ou paysans salariés, les entrepreneurs sont-ils plus en mesure de les faire mieux travailler contre rétribution? La question demeure.

11 Cet ouvrage, fruit d'un important dépouillement d'archives, apporte de nombreux exemples de la multiplication des documents administratifs standardisés au $\mathrm{xvIII}^{\mathrm{e}}$ siècle et de l'institutionnalisation d'une réquisition en travail qui a fait couler beaucoup d'encre. Si toutes les questions posées dans cet ouvrage n'ont pas de réponses claires, faute de sources, elles apportent néanmoins la démonstration que l'histoire économique, celle de l'administration et celle du travail sont maintenant mobilisées pour apporter un regard nouveau sur des institutions d'Ancien Régime et leur contribution à l'économie du royaume.

\section{AUTEURS}

\section{MICHÈLE VIROL}

Normandie Université, université de Rouen-Normandie, GRHis 